\title{
Evaluation of Different Techniques in Diagnosing Chlamydial Endocervical Infection Among Egyptian Females
}

\author{
Naglaa H. Mohamed and Taghreed M. Sharaf* \\ Obstetrics and Gynecology Department and *Clinical Pathology \\ Department. Faculty of Medicine for Girls. \\ Al-Azhar University
}

\begin{abstract}
Objective: To detect the prevalence of Chlamydia. Trachomatis infection symptomatic and asymptomatic in Egyptian females and to evaluate the diagnostic utility of polymerase chain reaction (PCR), direct immunofluorescence technique (DIF), and enzyme-linked immunosorbent assay (ELISA) for detection of $\mathrm{C}$ Trachomatis DNA, antigen and antibody respectively.

Study design: The study included 70 females who have been classified into :20 patients with tubal infertility, 15 patients with ectopic pregnancy, 20 patients with premature rupture of membrane (PROM) and 15 apparently healthy women (asymptomatic group). Endocervical specimens, vaginal swab and $3 \mathrm{ml}$ blood samples have been collected from all subjects and stored at $-20{ }^{\circ} \mathrm{C}$ till being processed. PCR,DIF and ELISA techniques have been done to detect C. Trachomatis DNA, antigen and antibody respectively.

Results: C. Trachomatis DNA was detected by PCR in the endocervix of 17 out of 55 infected cases $(30.9 \%$ ). however DIF technique was positive for $21.6 \%$ of patient groups and $13.3 \%$ of asymptomatic group. The tubal infertility group showed the highest percentage of active $\mathrm{C}$. Trachomatis infection $(45 \%)(\mathrm{P}<0.05)$ PCR showed better sensitivity than DIF for detection of C. Trachomatis infection $(96.2 \%$ versus $70 \%$ respectively), however both techniques had $100 \%$ specificity. Tubal infertility group showed highest sero prevalence $(45 \%)$, followed by ectopic pregnancy group $(35 \%)(\mathrm{P}=$ 0.001 and $\mathrm{P}<0.05$ respectively).

Conclusions: PCR procedure is suitable for confirmation of ELISA results in high-volume laboratories. Cost, experience of the laboratory personnel and the patient well-being must be taken into account to select the test for the detection of C.Trachomatis infections.
\end{abstract}




\section{Introduction}

Chlamydia Trachomatis is a small obligate intracellular parasite frequently implicated in sexually transmitted diseases such as cervicitis, non gono coccal urethritis and pelvic inflamm atory disease in women, and nongonococcal urethritis, epididymitis and proctitis in men. (1)

Symptoms of Chlamydia infect ion in women include: abnormal genital discharge, painful or frequent urination, burning or itching in vaginal area, redn -ess, swelling or soreness of the vulva or pain in the pelvis during sex. (2)

However, half of infected women and 25 percent of infected men may have no symptoms. As a result the disease is often not diagnosed until complications develop. $(3,4)$ Chlamydia in women can cause pelvic inflamm atory disease and thus potential infertility, ectopic pregnancy, Proctitis and Conjunctivitis. $(3,4)$

The infection can be passed from mother to the bay and may cause : premature rupture of membrane, prete rm birth, pneumonia and conjunctivitis of the baby's eyes. $(5,6)$

Additionally, recent studies of Levgur and Duvivier (7) suggested that chlamydial genital infections may be a risk factor facilitating sexual transm ission of HIV. For all these reasons improved means for prevention and control of early diagnosed cases are urgently needed. Culture on McCoy cell monolayer are considered to be the reference method for chlamydial detection, but the method is laborious and slow. (8)

A number of rapid test kits are commercially available for direct detection of Chlamydia trachomatis in endocervical specimens. These tests depend upon the use of either chlam ydial DNA probe or antichlamydial monoclonal antibodies as in the enzyme-linked immunosorbent assay or the direct fluorescent antibody staining technique. (9) All are good tests, but improvements in test sensitivity are an ongoing quest, specially for women with no symptoms.

The use of nucleic acid amplification methods such as polymerase chain reaction (PCR) and ligase chain reaction (LGR) have significantly improved the diagnosis of genital chlamydial infections, as they have been highly sensitive and specific and they are capable of detecting small amount of chlamydial DNA that are present in urine and self collected vaginal swabs that afford the opportunity to develop universal easy screening programs. (10, $11,12,13$ )

In this study, we aimed to detect the prevalence of C.Trachomatis infection among symptomatic and asymptomatic Egyptian females and its sequels, and to evaluate the diagnostic utility of PCR, direct immunofluorescence technique (DIF) and enzyme-linked immunos -orbent assay (ELISA) for detection of C. Trachomatis DNA, antigen and antibody respectively.

\section{Subjects and methods}

This study included 70 selected females attending the gynecology and obstetric Department of Al-Zahraa University hospital over a period of one year. They have been classified according to their full clinical history, examination, ultrasonography and lapa roscopic findings into three groups : tubal infertility (20 cases); ectopic pregnancy (15 cases) and premature rupture of membrane (20 cases) in addition to asymptomatic group who consists of 15 apparently healthy well 


\section{Evaluation of Different Techniques}

matched fertile females. Patients who had other factors of infertility, patient who have had antibiotics or pelvic surgery during the last two months were excluded from the study.

\section{Specimens collection :}

Three types of specimens have been collected from all subjects of the study. Endocervical specimens, vaginal swabs and $3 \mathrm{ml}$ clotted blood samples for separation of sera to be stored in a liquots at $-20 \circ \mathrm{C}$ till being processed.

The endocervical specimens were collected as follows :

1. Endocervical mucous was sucked with long insulin syring to detect polymorphonuclear leucocytes (PUNLS) by leukocyte estetase test kit and Leishman stain. (14)

2. Endocervical smear for detection of C. Trachomatis major router membrane protein (UOUP) antigen by DIF (Direct immunofluorescent).

3. Endocervical swaps for detection of C. Trachomatis DNA using PCR technique. (10). Endocervical and vaginal swabs were immersed immediately and separately in 800 $\mathrm{ml}$ of PCR lyses buffet and kept at $80{ }^{\circ} \mathrm{C}$ degrees till processing.

\section{Methods:}

1) Detection of polymorphonuclear leukocytes.

a- leukocyte esterase dipstick kit (LET) supplied by Bayet diagnostics which depends upon detection of granulocyte esterase.

b- Leishman stained smear for presence of > 5 PMNLS / HPF according to Mosciki et al. (14)

\section{2) Direct immunofluorescent technique (DIF).}

Pathfinder TM Fluorescein conjugated monoclonal antibody that react with MOMP of Trachomatis. A specimen was considered positive if $>5$ extracellular elementary bodies were detected per well. (photo 1)

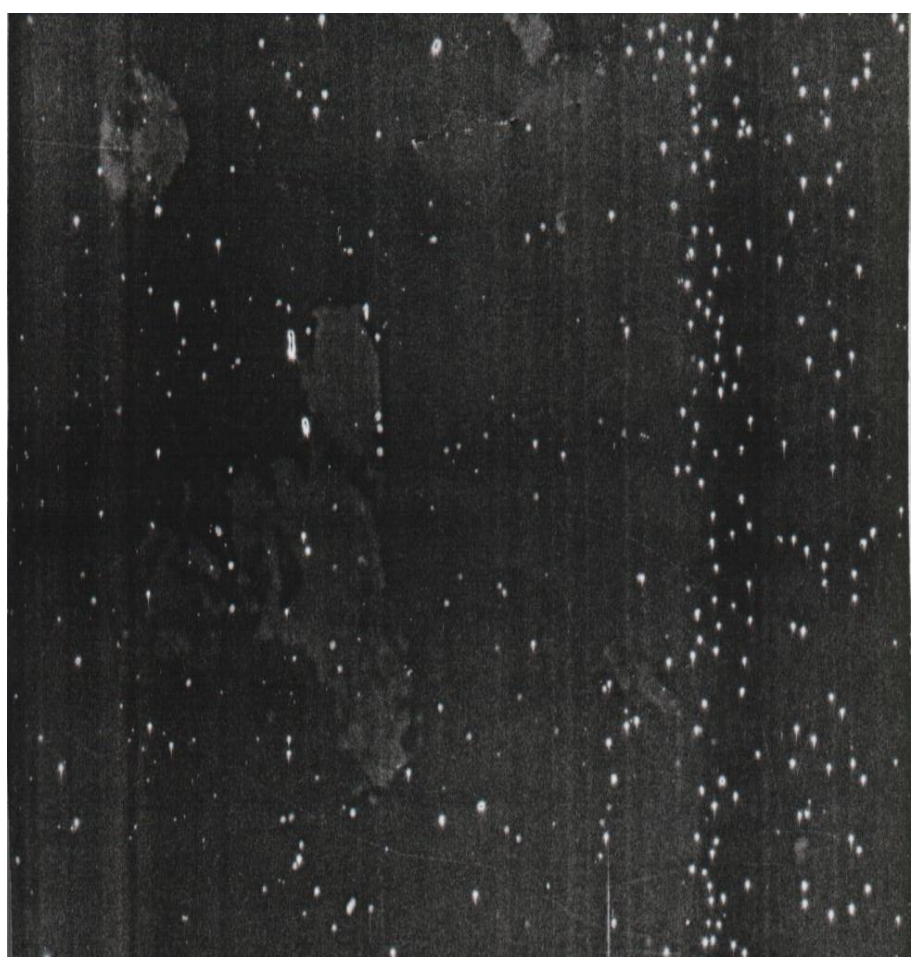

Photo (1) : Positive DIF for C. Trachomatis MOMP antigen (400x).

\section{3) polymerase chain reaction (PCR).}

It is used for detection of C. Trachomatis according to method of Dean et al (12) through 3 main steps.

- DNA extraction using proteinase $\mathrm{k}$ supplied by Boehringer Mannheim.

- DNA amplification.

- Detection of DNA specific products. The amplified reaction mixture was analyzed by electrophorisis on $1.5 \%$ agatose gel in tris acetate EDTA buffet stained with ethidium bromideztobe, visualized under ultraviolet transillum inator according to methods of Sambrook et al. (23) 


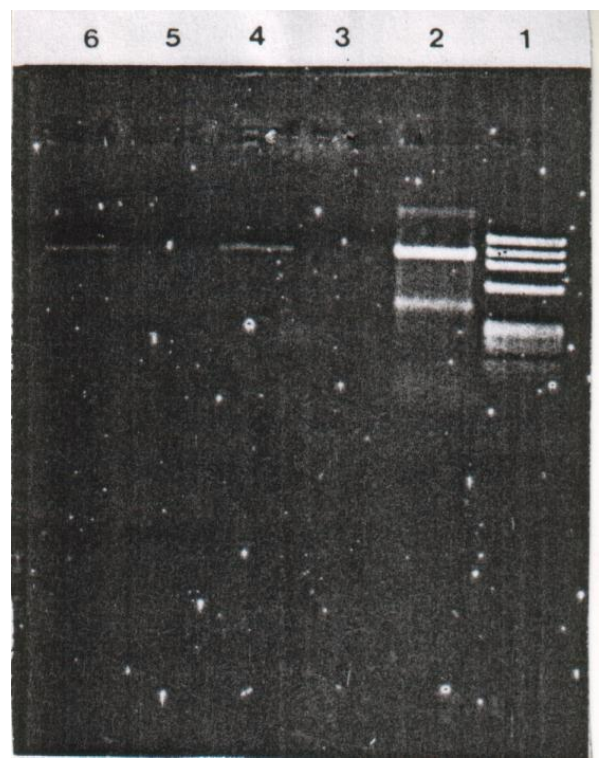

\section{Photo 2 : Electrophoretic separation of PCR amplified products}

Site 1 : DNA molecular weight marker : O x 174 Hall ( Boehringer Mannheim ) ranging in size from 72 to $1353 \mathrm{bp}$.

Site 2 : Positive control .

Site 3 : Negative control .

Site 4 \& 6 : positive PCR ( specific product ) samples .

Site 5 : Negative PCR sample .

\section{4)Enzyme-linked mmunosorbant assay (ELISA).}

Chlamydia Trachomatis IgG were detected using solid phase sandwich micro assay technique.

\section{Results}

C.Trachomatis DNA was detected by PCR in the endocervix of 17 out of 55 infected cases (30.9\%). Upon evaluation of PCR and DIF techniques, PCR was positive for $21.6 \%$. In addition, 2 out of 15 subjects $(13.3 \%)$ of asymptomatic group had active C.TRachomatis infection detec ted by any of the 2 techniques.
Among the 3 patient groups we found that the tubal infertility group showed the highest percentage of active C. Trachomatis infection (45\%) with a highly significant difference compared to asymptomatic group $(\mathrm{p}<0.05)$, wher eas this difference was insignificant in other groups (table 1).

PCR technique showed better sensitivity than DIF for the detection of active C. Trachomatis infection $(96.2 \%$ versus $70 \%$ ). However, both techniques had $100 \%$ specificity.

More over, sensitivity, specifi city, positive and negative predictive values for detection of PMNCs as a predictor of C. Trachomatis infection were $78 \%, 66.8 \%, 45 \%$ and $89.4 \%$ respectively for stained smear and $74 \%$, $65.5 \%, 51.2 \%$ and $89.4 \%$ respectively for LET.(Table 3)

Seraprevalence of C.Trachomatis IgG among studied groups revealed that tubal infertility showed highest seropr evalence (9 out of 20,45\%), followed by ectopic pregnancy (5 out of 15 , $35 \%$ ). This high seroprevalence in both groups was statistically significant versus asymptomatic group $(\mathrm{P}<0.001$ and $\mathrm{P}<0.05$ respectively).

$80 \%$ of cases of tubal infertility $(\mathrm{P}<0.001), 48 \%$ of cases of ectopic pregnancy $(\mathrm{P}<0.05)$ and $43 \%$ of cases with PROM ( $>0.05$, insignificant $)$ were detected by PCR technique.

Evaluation of vaginal introituses specimens versus endocervical samp ling sites using PCR technique revealed lower sensitivity of vaginal sites compared to endocervical ones for diff erent patients groups with no statistic ally significant difference $(\mathrm{P}>0.05)$ in cases with ectopic pregnancy, PROM and asymptomatic group. However, difference was statistically significant $(\mathrm{P}<0.05)$ as regards tubal infertility group.(Table2) Fig(1) 


\section{Evaluation of Different Techniques}

We found that vaginal $60 \%$ versus $100 \%$ for the control group. sensitivity in all patients groups was

Table (1) Chlamydia Trachomatis infection among the studied groups with different techniques used

\begin{tabular}{|c|c|c|c|c|c|c|c|c|}
\hline \multirow{3}{*}{ Techniques used } & \multicolumn{6}{|c|}{ Patients group } & \multirow{2}{*}{\multicolumn{2}{|c|}{$\begin{array}{l}\text { Asymptomatic group } \\
(\mathrm{no}=15)\end{array}$}} \\
\hline & \multicolumn{2}{|c|}{$\begin{array}{l}\text { Tubal infertility } \\
(\text { no }=20)\end{array}$} & \multicolumn{2}{|c|}{$\begin{array}{l}\text { Ectopic } \\
\text { pregnancy } \\
\text { (no=15) }\end{array}$} & \multicolumn{2}{|c|}{ PROM (no=20) } & & \\
\hline & No & $\%$ & No & $\%$ & No & $\%$ & No & $\%$ \\
\hline PCR & 9 & 45 & 2 & 13.3 & 6 & 30 & 2 & 13.3 \\
\hline DIF & 5 & 25 & 1 & 6.6 & 4 & 20 & 2 & 13.3 \\
\hline $\lg G$ & 11 & 55 & 5 & 35 & 6 & 30 & 2 & 13.3 \\
\hline \multirow{3}{*}{$\begin{array}{l}\text { PCR\&DIF } \\
X^{2} \\
P\end{array}$} & 9 & 45 & 2 & 13.3 & 6 & 30 & 2 & 13.3 \\
\hline & \multicolumn{2}{|c|}{1.303} & \multicolumn{2}{|c|}{4.892} & \multicolumn{2}{|c|}{1.280} & \multicolumn{2}{|c|}{0.899} \\
\hline & \multicolumn{2}{|c|}{$<0.05$} & \multicolumn{2}{|c|}{$>0.05$} & \multicolumn{2}{|c|}{$>0.05$} & \multicolumn{2}{|c|}{$>0.05$} \\
\hline $\lg \mathrm{G}, \mathrm{PCR} \& \mathrm{DIF}$ & & 55 & 5 & 35 & 6 & 30 & 2 & 13.3 \\
\hline $\mathrm{X}^{2}$ & \multicolumn{2}{|c|}{4.70} & \multicolumn{2}{|c|}{3.314} & \multicolumn{2}{|c|}{4.330} & & \\
\hline $\mathrm{P}$ & \multicolumn{2}{|c|}{$<0.001$} & \multicolumn{2}{|c|}{$<0.03$} & \multicolumn{2}{|c|}{$<0.05$} & & \\
\hline
\end{tabular}

$\mathrm{P}<0.001=$ highly significant

$\mathrm{P}<0.05=$ significant

Table (2) comparative evaluation af sampling sites using PCR techniques in different groups.

\begin{tabular}{|l|l|l|l|l|l|l|}
\hline & \multicolumn{2}{|l|}{ Endocervical swab } & \multicolumn{2}{l|}{ Vaginal swab } & \multirow{2}{*}{$\mathrm{X}^{2}$} & $\mathrm{P}$ \\
\cline { 2 - 7 } & $+\mathrm{ve}$ & $\%$ & $+\mathrm{ve}$ & $\%$ & 2.410 & $<0.05$ \\
\hline Tubal infertility no=50 & 23 & 46 & 13 & 26 & 0.652 & $>0.05$ \\
\hline $\begin{array}{l}\text { Ectopic pregnancy } \\
\text { no=20 }\end{array}$ & 14 & 14 & 2 & 10 & 0.267 & $>0.05$ \\
\hline PROM no=50 group & 15 & 30 & 10 & 20 & - & - \\
\hline $\begin{array}{l}\text { Asymptomatic } \\
\text { no=30 }\end{array}$ & 1 & 3.3 & 0 & 0 & - & \\
\hline
\end{tabular}

$\mathrm{P}<0.05=$ highly significant

$\mathrm{P}>0.05=$ no significant

Table (3): Statistical evaluation of PCR, DIF and presence of PMNLs as a predictor for the detection of active cervical chlamydia infection.

\begin{tabular}{|c|c|c|c|c|}
\hline Test & Sensitivity \% & Specificity \% & $\begin{array}{c}\text { Positive } \\
\text { predictive value }\end{array}$ & $\begin{array}{c}\text { Positive } \\
\text { predictive value }\end{array}$ \\
\hline PCR & 96.2 & 100 & 100 & 98.4 \\
\hline DIF & 70 & 100 & 100 & 88.5 \\
\hline Detection of PMNLs & 78 & 66.8 & 45 & 89.4 \\
Stained smear LET & 74 & 65.5 & 51.2 & 89.4 \\
\hline
\end{tabular}


Fig (1) show comparative evaluation of sample site using PCR technique in different group.

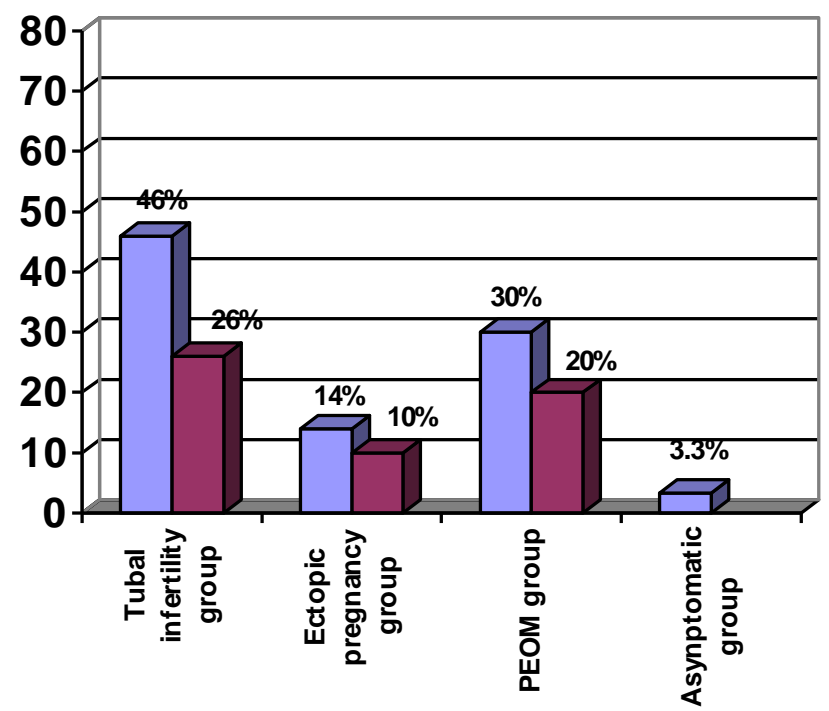

$\square$ Endoceruical Swat
$\square$ Vaginal Swab

\section{Discussion:}

Most urogenital C. Trachomatis infections are initially asymptomatic but may subsequently cause considerable long-term morbidity. Consequently, accurate diagnosis of $\mathrm{C}$. Trachomatis infection requires the use of specific laboratory techniques. However there is no clinical or microbiological reference standered for diagnosis of $\mathrm{C}$. Trachomatis infection. (15) culture was earlier considered the gold standard, however PCR studies suggest that the sensitivity of the culture even in expert laboratories is as low as 75 to $85 \%$ and is no longer considered a reference method of new diagnosis assay. (16)

In our study, we found the highest prevalence of $\mathrm{C}$. Trachomatis infection was among women with tubal infertility $(45 \%)$ followed by PROM (30\%) and lastly ectopic pregnancy $(13.3 \%)$. This results were proved previously in many studies (10.19).

Differences in prevalence may be just a reflection of the improvement in the sensitivity and specificity of laboratory testing methods which have created a potential problem with interpr -eting data on Chlamydia prevalence trends.

El-Shourbagy et al (10) through using DIF technique showed a higher prevalence rate of Chlamydia infections in patients with ectopic pregnancy (77\%) and PROM (44\%). Our lower results may be a response to the recent development of public health programs sensitizing women to complications of C. Trachomatis infections and the empirical treatment of lower genital tract infection with widespread use of newer antibiotics especially azithromax that can both penetrate the tissue and sustain longer half-life.(1)

In addition, the estimated prevalence of $\mathrm{C}$. Trachomatis infection by PCR in our asymptomatic group was $13.3 \%$, whereas, the previously recor ded prevalence in Egypt was 17.2\% (10). In USA, Dicker et al, (21) reported a prevalence of $4.1 \%$ upon using PCR technique. In Amsterdam, Panuco et al. (22) recorded a prevalence among population of $2.4 \%$. this revealed the 
high prevalence rate of a symptomatic active C. Trachomatis infection among Egyptian females.

For the molecular diagnosis of active C. Trachomatis infection, we found that PCR technique was able to detect the endocervical DNA of MOMP gene with $96.2 \%$ sensitivity and 100\% specificity.

Several investigators $(14,17,18)$ reported sensitivity of $93.8 \%-100 \%$ using the same primers. There are PCR inhibitors that could be detected through the use of internal control and the performance of another extraction method to negative PCR specimen (18, $6,19)$. So complete and effective remo val of PCR inhibitors verify $100 \%$ PCR sensitivity. Thus DNA amplification based tests are ideally suitable for screening as they exhibit high sensitiv ity and specificity.

We found that DIF sensitivity and specificity were $70 \%$ and $100 \%$ respectively. Similarly, several studies revealed that DIF specificity of $100 \%$ and sensitivity of $70-84 \%$, yet more sensitive than other cytologic means of diagnosing $\mathrm{C}$. Trachomatis infection although less sensitive than culture and PCR (14).

The sensitivity, specificity, PPV (Positive Predictive Value) and NPV (Negative Predictive Value) of detection of PMNCs to predict Chlamydia infection were $76 \%, 65.6 \%, 46 \%$ and $87.5 \%$ respectively for stained smears and $77 \%, 67 \%, 49 \%$ and $87.5 \%$ respectively for LET. Mosciki etal.(14) and El-Shourbagy etal (20) found significant association of PMNCs in endocervical mucus with C. Tracho matis infection. So, it can predict women at risk for infection. The lower sensitivity and PPV recorded in our study versus the previous studies were attributed to their verification of the detection of PMNCs with techniques of lower sensitivities than PCR, culture and DIF.

In consideration to ELISA for detection of C. Trachomatis IgG, we chose our cut off value as mean $+/$ 25OD as high significant limit to ensure good specificity and prevents cross reactivity.

Also, our findings were evalu ated in concordance with active infection as serological tests per se are rarely helpful in diagnosing diseases caused by C. Trachomatis. That is due to the high background of antichlamydial antibodies attributed to the high prevalence of recurrent infection or due to seronegativity with persistant active infection.

Seropositivity with active infections denoted persistence or recurrent infection. However, seropos itivity without detection of C. Tracho matis antigen or DNA may be past infection with effective treatment, or active infection with $\mathrm{C}$. Trachomatis DNA below detection level of PCR or due to the presence of PCR inhibitors that account for $0.9-2.4 \%$ of total PCR positive specimen as previously recorded by Vincelette etal (6) and Van der Pol et al (19).

In our study, the tubal infertility and ectopic pregnancy groups showed high seropositivity $(52 \%$ and $35 \%$ respectively) which is statistically significant than asymptomatic group $(3.3 \%) \quad(\mathrm{P}<0.001 \quad$ and $\quad<0.05$ respectively). This finding was consistent with those of other investig ators $(10,15,19)$. These findings ensure the association between recurrent or persistent endocervical Clamydia infection and the increased risk of ectopic pregnancy $(9,10)$.

It was observed in this study that all patients positive for $\mathrm{C}$. Trachomatis DNA in vaginal dischange have PMNCs detected by either LET or in 
Leishman stained smears. This could be attributed to increases shedding of cervical epithelial cells associated with congestion and hyperemia due to inflammation. $(1,13,15,19)$

We concluded that, the PCR procedure is suitable for confirmation of ELISA results in high-volume laboratories, as it has a high concord ance rate compared to the rapid test. The sensitivity of ELISA can be improved by retesting specimens with OD (Opitic Density) values just below the cut off value, specially when a female population with a low prevalence of $\mathrm{C}$. Trachomatis infection is being examined. The rapid test should be thoroughly evaluated by applying it on a larger scale.

When selecting a test for the detection of C. Trachomatis infection, many factors must be taken into accounts, such as cost and experience of the laboratory personnel. The well being of the patient is also part of the decision. Additional studies will be required to evaluate both the costeffectiveness and head to head performance comparisons of different diagnostic tests among moderate and high prevalence populations and to determine the best approach for screening these populations,

\section{References}

1- Stamm, WE (1999) Chlamydia Trachomatis infection : progress and problems.J. Infect. Dis; 179:5380-5383

2- Cutes, W.J. and Wasserheit, J.N. (19941):Genital Chlamydia infections, epidemiology and reproductive sequelae. Am.J. Obstet. Gynecol; 164:1771-1781

3- Chiarini, f; Mansi, A and Tomao P (1994): Chlamydia Trachomatis genitourinary infections, laboratory diagnosis and therapeutic aspects.
Evaluation of in-vitra and in vivo effectiveness of erythromycin. J. Chemotet; 6(4):238-242

4- Hillis, S.D; Owens, L. Mand, March Banks. (1997). Recurrent chlamydial infections increase the risks of hospitalization for ectopic pregnancy and pelvic inflammation disease. AM.J. obstet. Gynecol; 176:103-107

5- Pate, S; Dixon, B. and Hardy K. (1998) Evaluation of biostarchlamydia OIA assay with specimens from women attending a sexually transmitted disease clinic.J.Clin Microbiol;36:21832186

6- Vincelette, J; Schirm, J. and Anne M. (1999) Multicenter evaluation of the fully customatedCOBAS amplicor PCR test for the detection of Chlamydia Trachomatis in urogenital specimens. J.Clin. Microbiol;37:74-80

7- Levgur, $M$ and Duvuvier (2000) Pelvic inflammatory disease after tubal sterilization. Obstet.Gynecol. sur.;55(1):41-60

8- Scholes, D.A., stergach is, F.E., Heindrich $\mathrm{H}$ and Stamm, WE (1996) Prevention of pelvic inflammatory disease by screening of cervical Chlamydia infection $\mathrm{N}$. Engl. J. Med.; 334:1362-1366.

9- sierra UF, Clarke LM, and Boyle JF(1998).. The laboratory diagnosis of Chlamydial infections. Lab Med ;19:311-314

10- El-Shourbagy, M; Abd ElMaeboud, k and Diab, k (1996) Genital Chlamydia Trachomatis infection in Egyptian women: incidence among different clinical risk groups. J.obstet. Gynecol. Res : 22 (95) : 467-472

11- Black, C.M. (1997) current methods of laboratory diagnosis of Clamydia 
infection.Clin. Microbiol. Rev; 10:160-184

12- Dean D.; Ferrero, Dand, McCarthy, M (1998) Comparison of performance and last effectiveness of Chlamydial enzyme immunoassay results for populations with a low to moderate prevalence of Clanydia Trachomatis infection. J.Clin. Microbiol 46:94-99

13- Stary, A; Schuh, E.; Kerschbaumer, m.; Gotz, B. and Lee H. (1998): performance of transcription-mediated

amplification and ligase chain reaction assays fir detection of Chlamydial infections in uroigenital samples obtained by invasive and non-invasive methods.L.Clin. Microbiol.; 36(9):2666-2670.

14- Moscoki, B.; Mary, S.; Susan, G. and Schachter, J. (1987): the use and limitations of endocervical gram stain and mucopurulent cervicitis as predictors for $\mathrm{C}$, Trachomatis in female adolescents. Am.J Obstet.Gynecol.;157:65-71.

15- Ostergaard, L. (1999): diagnosis of urogenital Chlamydia Trachomatis infection byn use of DNA amplification. APMIS; suppl. 89:5-36.

16- Hagdu, A. (1996): the discrepancy in discrepant analysis. Lancet; 348:592-593.

17- Bobo, L.; Coutlee, R.; Yolken, H.; Quinn, T. and Viscidi, P. (1990): Diagnosis of Chlamydia Trachomatis cervical infection by detection of amplified DNA wi8th an enzyme immunoassay. J.Clin.Microbiol.;28:1968-1973.

18- Loeffetholz, M.J; Lewinski, C.A. and Silver, A..P. (1992) :Detection of Chlamydia
Trachomatis in endocervical specimens by polymerase chain reaction. J.Clin.Microbiol; 60:2847-2851

19- Van Der Pol, B.; Quinn, TC.; Gaydos, C.A.;Crothfelt, K.; Schachter, J.; Moncada, J.; Jug kind, D.; Martin, D.H.; Turner, B.; Peyto9n, V and Jones, K.B. (2000): Multicenter evaluation of AMPLICOR CT/NG test for detection of Chlamydia Trachomatis. J.Clin,Microbiol.; 38(3):1105-1112

20- El-Shourbagy, M.; Diab, K.; Abdalla, Y; Abd El-Salam, M. and Mohasb, S. (1998) : The usefulness os screening for Chlamydia Trachomatis infection with cervical mucus leukocyte esterase. J.Obstet.Gynecol.Res.:24:21-25

21- Dicker, L.W.; Mosure, D.J.; Levine, W.C.; Btack, C.M. and Berman, S.M. (2000) : impact of switching laboratory tests on reported trends in Chlamydia Trachomatis infections. Am.J.Epidemiol.; 151(4):430435.

22- Claman, P.; Honey, L.; Peeling, R.W. and Tove, B. (1997) : the presence of serum antibody to the chlamydial heat shock protein (Ahsp6O) as a diagnostic test for tubal factor infertility. Fertil. Steril.; 67(3):501-504

23-Sambrook, J.; Fritsh, E.F. and Mniatis, T. (1989): Molecular cloning. In: A Laboratory Manual, second edition, p:89-96. Cold Spring Harbor Press, NY.

24-Ryan, R.W., Kwasnik, I. And Tilton, R.C. (1986): Rapid detection of Chlamydia Trachomatis by enzyme immuno assay method. Diagn. Microbiol. Infect. Dis., 5:225-234. 


\section{تقييم الوسائل المختلفة في تثخيص العدوى بالكلاميديا في عنق الرحم بين السيدات المصريات .}

"د . تغربا محد شرف .

لـ . نجلاء حسبي محمد

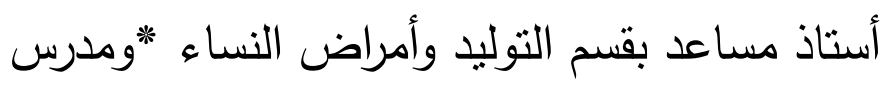

بقسم الباثولوجيا الإكلينيكية بكلية طب بنات الأزهر

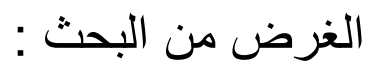

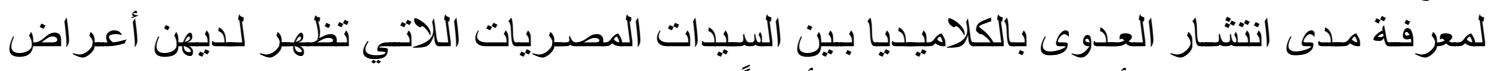

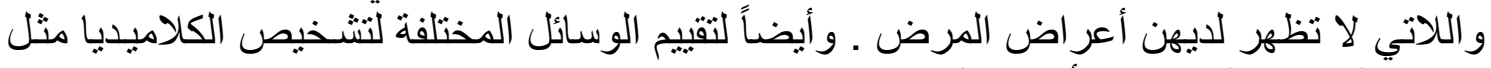

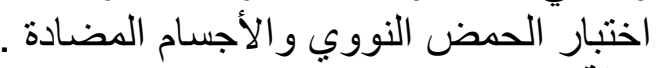
خطة البحث :

وقد أجرى هذا البحث علي 70 سيدة وتم تقسيمهن كالتالي :-

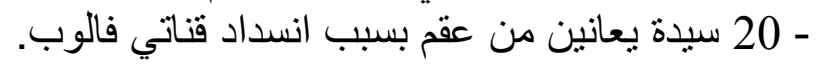

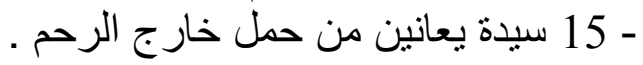

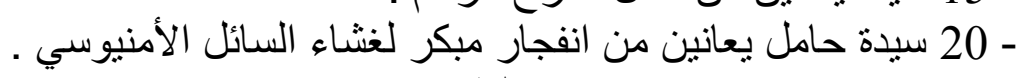

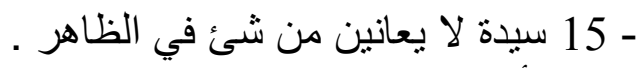

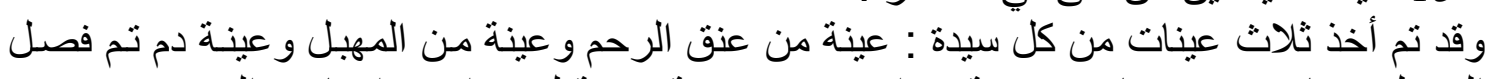

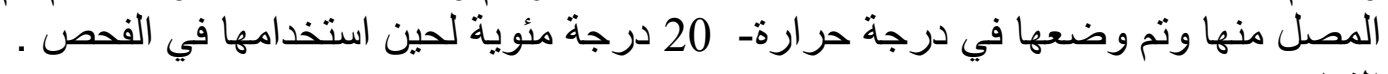
النتائج : النمل

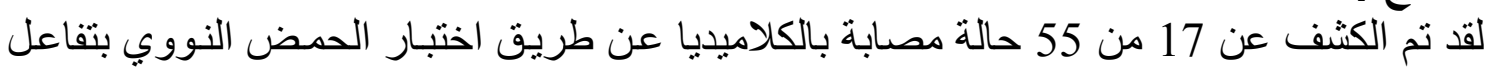

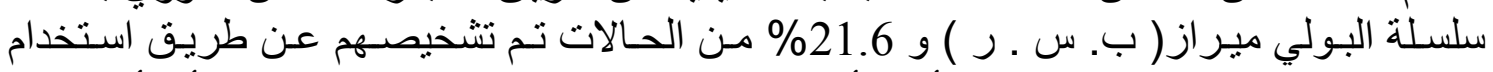

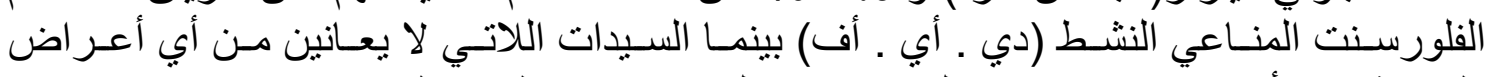

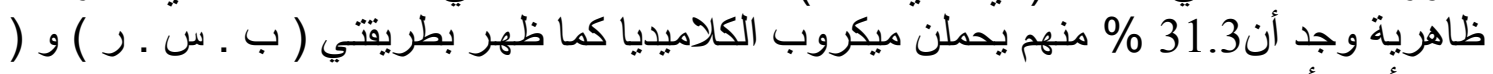

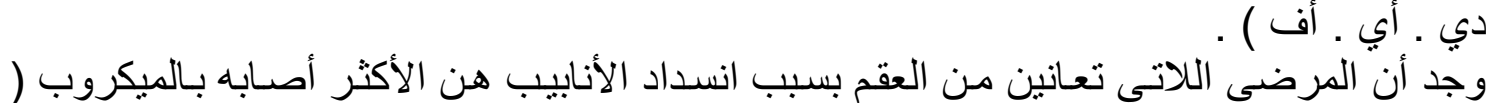

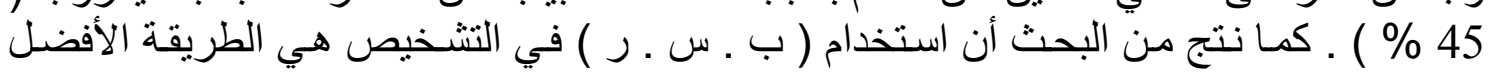
حساسية وخصوصية . كمانج الاستتناج:

نستخلص من هذا البحث أنة توجد طرق عديدة لتشخيص الاتهاب بالكلايميديا.

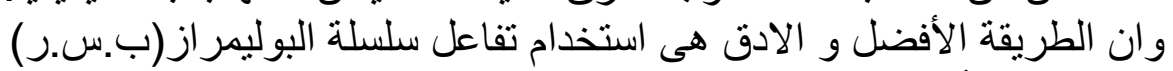

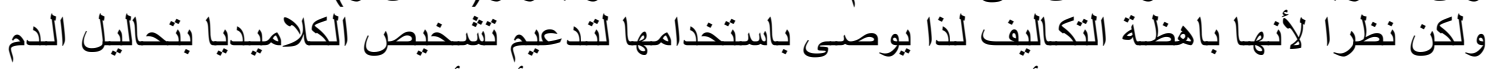

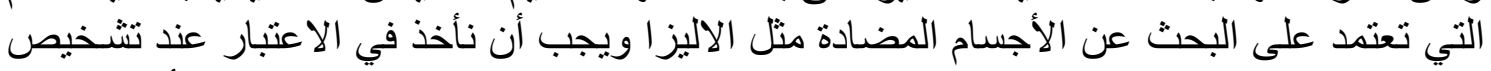

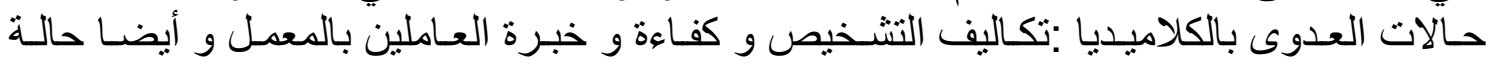
المريضة وذللك حتى يسهل علينا اختيار الوسيلة المتلى للتشخيص. 